\title{
OPEN Mexiletine-like cellular electrophysiological effects of GS967 in canine ventricular myocardium
}

\author{
Tamás Hézső ${ }^{1,10}$, Muhammad Naveed ${ }^{2,10}$, Csaba Dienes ${ }^{1}$, Dénes Kiss ${ }^{1}$, János Prorok ${ }^{2,3}$, \\ Tamás Árpádffy-Lovas ${ }^{2}$, Richárd Varga ${ }^{2}$, Erika Fujii ${ }^{1}$, Tanju Mercan ${ }^{4}$, Leila Topal ${ }^{2}$, \\ Kornél Kistamás ${ }^{1}$, Norbert Szentandrássy ${ }^{1,5}$, János Almássy ${ }^{1}$, Norbert Jost ${ }^{2,3}$, \\ János Magyar ${ }^{1,6}$, Tamás Bányász $^{1}$, István Baczkó ${ }^{2,7}$, András Varró ${ }^{2,3,7 凶}$, Péter P. Nánási ${ }^{1,8}{ }^{\circledR}$, \\ László Virág ${ }^{2,7,11} \&$ Balázs Horváth ${ }^{1,9,11}$
}

Enhancement of the late $\mathrm{Na}^{+}$current $\left(\mathrm{I}_{\mathrm{NaL}}\right)$ increases arrhythmia propensity in the heart, while suppression of the current is antiarrhythmic. GS967 is an agent considered as a selective blocker of $I_{\mathrm{NaL}}$. In the present study, effects of GS967 on $I_{\mathrm{NaL}}$ and action potential (AP) morphology were studied in canine ventricular myocytes by using conventional voltage clamp, action potential voltage clamp and sharp microelectrode techniques. The effects of GS967 $(1 \mu \mathrm{M})$ were compared to those of the class $\mathrm{I} / \mathrm{B}$ antiarrhythmic compound mexiletine $(40 \mu \mathrm{M})$. Under conventional voltage clamp conditions, $\mathrm{I}_{\mathrm{NaL}}$ was significantly suppressed by GS967 and mexiletine, causing $80.4 \pm 2.2 \%$ and $59.1 \pm 1.8 \%$ reduction of the densities of $I_{\mathrm{NaL}}$ measured at $50 \mathrm{~ms}$ of depolarization, and $79.0 \pm 3.1 \%$ and $63.3 \pm 2.7 \%$ reduction of the corresponding current integrals, respectively. Both drugs shifted the voltage dependence of the steady-state inactivation curve of $I_{\text {NaL }}$ towards negative potentials. GS967 and mexiletine dissected inward $I_{\mathrm{NaL}}$ profiles under AP voltage clamp conditions having densities, measured at $50 \%$ of AP duration (APD), of $-0.37 \pm 0.07$ and $-0.28 \pm 0.03 \mathrm{~A} / \mathrm{F}$, and current integrals of $-56.7 \pm 9.1$ and $-46.6 \pm 5.5$ $\mathrm{mC} / \mathrm{F}$, respectively. Drug effects on peak $\mathrm{Na}^{+}$current $\left(\mathrm{I}_{\mathrm{NaP}}\right)$ were assessed by recording the maximum velocity of AP upstroke $\left(\mathrm{V}^{+}{ }_{\text {max }}\right)$ in multicellular preparations. The offset time constant was threefold faster for GS967 than mexiletine (110 ms versus $289 \mathrm{~ms})$, while the onset of the rate-dependent block was slower in the case of GS967. Effects on beat-to-beat variability of APD was studied in isolated myocytes. Beat-to-beat variability was significantly decreased by both GS967 and mexiletine (reduction of $42.1 \pm 6.5 \%$ and $24.6 \pm 12.8 \%$, respectively) while their shortening effect on APD was comparable. It is concluded that the electrophysiological effects of GS967 are similar to those of mexiletine, but with somewhat faster offset kinetics of $\mathrm{V}^{+}{ }_{\text {max }}$ block. However, since GS967 depressed $\mathrm{V}^{+}{ }_{\max }$ and $\mathrm{I}_{\mathrm{NaL}}$ at the same concentration, the current view that GS967 represents a new class of drugs that selectively block $I_{\mathrm{NaL}}$ has to be questioned and it is suggested that GS967 should be classified as a class I/B antiarrhythmic agent.

\footnotetext{
${ }^{1}$ Department of Physiology, Faculty of Medicine, University of Debrecen, Nagyerdei krt 98, 4012 Debrecen, Hungary. 'Department of Pharmacology and Pharmacotherapy, Faculty of Medicine, University of Szeged, Dóm tér 12, 6701 Szeged, Hungary. ${ }^{3}$ MTA-SZTE Research Group for Cardiovascular Pharmacology, Hungarian Academy of Sciences, Szeged, Hungary. ${ }^{4}$ Department of Biophysics, School of Medicine, Akdeniz University, Antalya, Turkey. ${ }^{5}$ Department of Basic Medical Sciences, Faculty of Dentistry, University of Debrecen, Debrecen, Hungary. ${ }^{6}$ Division of Sport Physiology, Department of Physiology, Faculty of Medicine, University of Debrecen, Debrecen, Hungary. ${ }^{7}$ Department of Pharmacology and Pharmacotherapy, Interdisciplinary Excellence Centre, University of Szeged, Szeged, Hungary. ${ }^{8}$ Department of Dental Physiology and Pharmacology, Faculty of Dentistry, University of Debrecen, Debrecen, Hungary. ${ }^{9}$ Faculty of Pharmacy, University of Debrecen, Debrecen, Hungary. ${ }^{10}$ These authors contributed equally: Tamás Hézső and Muhammad Naveed. ${ }^{11}$ These authors jointly supervised this work: László Virág and Balázs Horváth. ${ }^{\boxplus}$ email: varro.andras@med.u-szeged.hu; nanasi.peter@ med.unideb.hu
} 
Following the large $\mathrm{Na}^{+}$current surge associated with the AP upstroke (called $\mathrm{I}_{\mathrm{NaP}}$ ) a smaller but sustained current component (called $\mathrm{I}_{\mathrm{NaL}}$ ) remains active throughout the entire cardiac AP. Enhanced $\mathrm{I}_{\mathrm{NaL}}$, due to diseases like heart failure ${ }^{1-3}$, hypertrophic cardiomyopathy ${ }^{4}$ or LQT3 ${ }^{5}$, is known to increase arrhythmia propensity in the heart ${ }^{1,6-8}$. It has been known for a long time that many of the class I antiarrhythmic drugs inhibit $\mathrm{I}_{\mathrm{NaL}}$ in addition to blocking $\mathrm{I}_{\mathrm{NaP}}{ }^{9-14}$. This latter effect, however, was considered to enhance proarrhythmic risk and consequently the incidence of sudden cardiac death ${ }^{15}$. As a consequence, development of agents to suppress $\mathrm{I}_{\mathrm{NaL}}$ selectively was a straightforward strategy in the past decades ${ }^{2,16-19}$. One of these agents, 6-(4-(trifluoromethoxy) phenyl)-3-(trifluoromethyl)-[1,2,4] triazolo[4,3-a]pyridine, known as GS967 or GS458967, was reported to be a particularly selective candidate when tested in rabbit ventricular cells ${ }^{16}$. It was also shown that important speciesdependent variations existed in the electrophysiological properties of myocardial preparations ${ }^{20,21}$, and canine ventricular myocytes are considered a reasonably good model for human ventricular cells $\mathrm{s}^{22-24}$. Furthermore, it was previously shown using the action potential voltage clamp technique that the kinetic properties of $\mathrm{I}_{\mathrm{NaL}}$ are similar in dogs and humans ${ }^{20}$, while differing from those of other mammals including guinea pigs, rabbits and pigs $^{25-27}$. Therefore, we studied the effects of GS967 on $\mathrm{I}_{\mathrm{NaL}}$ and $\mathrm{AP}^{+}{ }_{\text {max }}$ (the indicator of $\mathrm{I}_{\mathrm{NaP}}$ ), comparing them to similar effects of the class I/B antiarrhythmic agent mexiletine in canine ventricular preparations. In this work, based on experimental evidence, we challenge the present concept that GS967 exerts a selective $\mathrm{I}_{\mathrm{NaL}}$ blocking effect, since it has very similar class I/B antiarrhythmic properties as mexiletine.

\section{Methods}

Animals. Adult mongrel dogs of either sex were anesthetized with i.m. injections of $10 \mathrm{mg} / \mathrm{kg}$ ketamine hydrochloride (Calypsol, Richter Gedeon, Hungary) $+1 \mathrm{mg} / \mathrm{kg}$ xylazine hydrochloride (Sedaxylan, Eurovet Animal Health BV, The Netherlands) according to a protocol approved by the local Animal Care Committees (license $N^{\circ}$ : 9/2015/DEMÁB at University of Debrecen; and I-74-15-2017, I-74-24-2017 at University of Szeged) and by the Department of Animal Health and Food Control of the Ministry of Agriculture and Rural Development (XIII/3330/2017 and XIII/3331/2017). All animal procedures conform to the guidelines from Directive 2010/63/EU of the European Parliament on the protection of animals used for scientific purposes and the Guide for the Care and Use of Laboratory Animals (USA NIH publication NO 85-23, revised 1996) The study was carried out in compliance with the ARRIVE guidelines.

Isolation of cardiomyocytes. Single canine myocytes were obtained by enzymatic dispersion using the segment perfusion technique, as previously described ${ }^{28}$. Briefly, a wedge-shaped section of the ventricular wall supplied by the LAD coronary artery was cannulated, dissected and perfused with a nominally $\mathrm{Ca}^{2+}$-free Joklik solution (Minimum Essential Medium Eagle, Joklik Modification, Sigma-Aldrich Co. St. Louis, MO, USA) for a period of $5 \mathrm{~min}$. After this, the tissue was perfused with Joklik solution supplemented with $1 \mathrm{mg} / \mathrm{ml}$ collagenase (Type II, Worthington Biochemical Co., Lakewood, NJ, USA; representing final activity of $224 \mathrm{U} / \mathrm{ml}$ ) and $0.2 \%$ bovine serum albumin (Fraction V., Sigma) containing $50 \mu \mathrm{M} \mathrm{Ca}^{2+}$ for $30 \mathrm{~min}$. Finally, the normal external $\mathrm{Ca}^{2+}$ concentration was gradually restored and the cells were stored at $15{ }^{\circ} \mathrm{C}$ in Minimum Essential Medium Eagle until use. The chemicals used in the experiments were obtained from Sigma-Aldrich Co. (St. Louis, MO, USA), except for GS967, which was purchased from MedKoo Biosciences, Inc. (Morrisville, NC, USA).

Electrophysiology. Cells were placed in a plexiglass chamber under an inverted microscope, allowing for continuous superfusion with a modified Tyrode solution by gravity flow at a rate of $1-2 \mathrm{ml} / \mathrm{min}$. The modified Tyrode solution contained (in $\mathrm{mM}$ ): $\mathrm{NaCl} 121, \mathrm{KCl} 4, \mathrm{CaCl}_{2} 1.3, \mathrm{MgCl}_{2} 1, \mathrm{HEPES} 10, \mathrm{NaHCO}_{3} 25$, glucose 10 at $\mathrm{pH}=7.35$, which was supplemented according to the actual experimental design. The osmolarity of this solution was $300 \pm 3 \mathrm{mOsm}$, measured with a vapor pressure osmometer. In all experiments, the bath temperature was set to $37^{\circ} \mathrm{C}$ using a temperature controller (Cell MicroControls, Norfolk, VA, USA). Electrical signals were amplified and recorded (MultiClamp 700A or 700B, Molecular Devices, Sunnyvale, CA, USA) under the control of a pClamp 10 software (Molecular Devices) following analogue-digital conversion (Digidata 1440A or 1332, Molecular Devices). Electrodes, having tip resistances of 2-3M $\Omega$ when filled with pipette solution, were manufactured from borosilicate glass. Transmembrane currents were recorded in whole-cell voltage clamp configuration. The series resistance was typically $4-8 \mathrm{M} \Omega$, and the measurement was discarded if it changed substantially during the experiment.

Action potential voltage clamp. Action potential voltage clamp experiments were performed according to the methods described ${ }^{29,30}$. A previously recorded midmyocardial canine ventricular AP was applied as command signal and the current traces were recorded continuously in modified Tyrode solution before and after 5 min superfusion with the $\mathrm{Na}^{+}$channel inhibitor applied. The drug-sensitive current was obtained by subtracting the post-drug trace from the reference pre-drug trace. When measuring the effects of GS967 or mexiletine on $\mathrm{I}_{\mathrm{NaL}}$, the experiments were performed in the presence of $1 \mu \mathrm{M}$ nisoldipine $+1 \mu \mathrm{M}$ E4031 $+100 \mu \mathrm{M}$ chromanol 293B, added to the Tyrode solution, in order to eliminate any interference from $\mathrm{Ca}^{2+}$ and $\mathrm{K}^{+}$currents. The pipette solu-

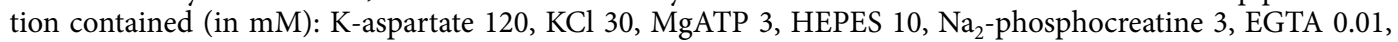
cAMP $0.002, \mathrm{KOH} 10$ at $\mathrm{pH}=7.3$ with an osmolarity of $285 \mathrm{mOsm}$. The amplitude of the dissected $\mathrm{I}_{\mathrm{NaL}}$ was evaluated at $50 \%$ duration of the $\mathrm{APD}_{90}$ value of the command $\mathrm{AP}$. When determining the current integral, the initial $20 \mathrm{~ms}$ after the AP upstroke was excluded from evaluation in order to eliminate the contribution of $\mathrm{I}_{\mathrm{NaP}}$. In each experiment 20 consecutive current traces were averaged and analyzed in order to reduce the noise and the trace-to-trace fluctuations of action potential configuration. Ion currents were normalized to cell capacitance, determined in each cell by applying hyperpolarizations from +10 to $-10 \mathrm{mV}$ for $15 \mathrm{~ms}$. 
Conventional voltage clamp. Conventional voltage clamp experiments, using rectangular command pulses, were performed to study the effects of GS967 and mexiletine on $\mathrm{I}_{\mathrm{NaL}}$ at stable test potentials. The external solution was a HEPES-buffered Tyrode solution containing (in $\mathrm{mM}$ ): $\mathrm{NaCl} 144, \mathrm{NaH}_{2} \mathrm{PO}_{4} 0.4, \mathrm{KCl} 4.0, \mathrm{CaCl}_{2} 1.8$, $\mathrm{MgSO}_{4} 0.53$, glucose 5.5 and HEPES 5.0, at $\mathrm{pH}=7.4$ ) supplemented with $1 \mu \mathrm{M}$ nisoldipine, $0.5 \mu \mathrm{M}$ HMR-1556 and $0.1 \mu \mathrm{M}$ dofetilide in order to block $\mathrm{Ca}^{2+}$ and $\mathrm{K}^{+}$currents. The composition of the pipette solution was (in $\mathrm{mM}$ ): $\mathrm{CsCl} 125$, TEACl 20, MgATP 5, EGTA 10, HEPES 10, at a $\mathrm{pH}=7.2$ ). Test pulses were clamped to $-20 \mathrm{mV}$ for $2 \mathrm{~s}$ from the holding potential of $-120 \mathrm{mV}$ before and after application of GS967 or mexiletine, while the total amount of $\mathrm{I}_{\mathrm{NaL}}$ was determined by pharmacological subtraction performed by a final superfusion with $20 \mu \mathrm{M}$ TTX. The amplitude of $\mathrm{I}_{\mathrm{NaL}}$ was evaluated at $50 \mathrm{~ms}$ after beginning the pulse. For determination of current integral the initial $20 \mathrm{~ms}$ was excluded from evaluation in order to minimize the contribution of $\mathrm{I}_{\mathrm{NaP}}$. In order to study the voltage-dependence of steady-state inactivation of $\mathrm{I}_{\mathrm{NaL}}$, test depolarizations to $-20 \mathrm{mV}$ were preceded by a set of $2 \mathrm{~s}$ long prepulses clamped to various voltages between -130 and $-40 \mathrm{mV}$ for $2 \mathrm{~s}$. Peak currents measured after these prepulses $\left(\mathrm{I}_{\text {test }}\right)$ were normalized to the peak current measured after the $-130 \mathrm{mV}$ prepulse $\left(\mathrm{I}_{\max }\right)$ and these $\mathrm{I}_{\text {test }} / \mathrm{I}_{\max }$ ratios were plotted against the respective prepulse potentials. The data were fitted to the two-state Boltzmann function $(\mathrm{y}=100 /[1+\exp ((\mathrm{x}-\mathrm{V} 1 / 2) / \mathrm{k})])$.

Recording of APs from multicellular preparations. Multicellular preparations (right ventricular papillary muscles) were selected to prevent the limitations of isolated myocyte studies, like the absence of intercellular clefts or potential damage to channel proteins, allowing better representation of in vivo conditions. The experiments were performed as previously described ${ }^{31}$. Briefly, transmembrane potentials were recorded using $3 \mathrm{M} \mathrm{KCl} \mathrm{filled}$ sharp glass microelectrodes having tip resistance between 10 and $20 \mathrm{M} \Omega$. These electrodes were connected to the input of a high impedance electrometer (MDE GmbH, Heidelberg, Germany). Preparations were paced by a pair of platinum electrodes using $1 \mathrm{~ms}$ wide rectangular current pulses with twice the threshold amplitude at $37^{\circ} \mathrm{C}$. The pacing cycle length was set to $1 \mathrm{~s}$ for at least $60 \mathrm{~min}$ allowing the preparations to equilibrate before starting the experiment.

Following equilibration at $1 \mathrm{~s}$ cycle length, the cycle length was sequentially varied between 0.3 and $5 \mathrm{~s}$. At each cycle length the 25th AP was recorded, and the cycle length was then changed. Under these conditions a quasi steady-state rate-dependence could rapidly be obtained. APs were digitized at $100 \mathrm{kHz}$ using an ADA 3300 data acquisition board (Real Time Devices Inc., State Collage, PA, USA) and stored for later analysis. After taking control records at each cycle length the preparations were superfused with either GS967 or mexiletine for 20 min and then the protocol was repeated. Efforts were made to maintain the same impalement throughout each experiment. If, however, an impalement became dislodged, adjustment was attempted, but when the parameters of the re-established impalement deviated by more than $5 \%$ from the previous record, the experiment was discarded.

Restitution kinetics of the maximum rate of depolarization $\left(\mathrm{V}^{+}{ }_{\text {max }}\right)$ is considered as the indicator of the offset time constant. To determine the restitution time constant for $\mathrm{V}^{+}{ }_{\max }$ the preparations were paced using a train of 20 basic stimuli delivered at a basic cycle length of $1 \mathrm{~s}$. Each train was followed by a single extra stimulus applied with successively longer coupling intervals. The train of basic stimuli was reinitiated following the delivery of the extra stimulus. In this way, each 20th basic AP was followed by a single extra AP occurring at gradually increasing diastolic intervals. The diastolic interval was defined as the time from $\mathrm{APD}_{90}$ of the last basic member of the train to the upstroke of the extra AP. Recovery curves were generated by plotting the $\mathrm{V}^{+}{ }_{\max }$ of each extra AP as a function of the respective diastolic interval and data were fitted to a single exponential function.

Onset kinetics of drug action on $\mathrm{V}^{+}$max were determined by stimulating the preparation at a cycle length of $0.4 \mathrm{~s}$ following a few min period of rest and the initial 40 APs were recorded and data were plotted against the number of the analyzed AP within the train. The rate of development of block was obtained by monoexponential fitting of the $\mathrm{V}^{+}{ }_{\max }$ values.

Determination of beat-to-beat variability of APD in isolated myocytes. Since beat-to-beat variability of APD is relatively small in multicellular preparations due to the balancing effect of the neighboring cells, these experiments were performed in isolated myocytes. Series of 50 consecutive action potentials were analyzed to estimate the beat-to-beat variability of APD, defined as short term variability (SV), according to the following formula:

$$
\mathrm{SV}=\Sigma\left(\left|\mathrm{APD}_{\mathrm{i}+1}-\mathrm{APD}_{\mathrm{i}}\right|\right) /\left[\mathrm{n}_{\text {beats }} * \sqrt{ } 2\right]
$$

where SV is short term variability, $\mathrm{APD}_{\mathrm{i}}$ and $\mathrm{APD}_{\mathrm{i}+1}$ indicate the durations of the ith and $\mathrm{i}+1$ th $\mathrm{APs}$, respectively, at $90 \%$ level of repolarization and $n_{\text {beats }}$ denotes the number of consecutive beats analyzed ${ }^{32}$. Changes in SV were presented as Poincaré plots where 50 consecutive APD values are plotted, each against the duration of the previous AP.

Statistics. Results are expressed as mean \pm SEM values, $\mathrm{n}$ denotes the number of myocytes or multicellular preparations studied. Statistical significance of differences was evaluated using one-way ANOVA followed by Student's t-test for paired or unpaired data as pertinent. Differences were considered significant when $\mathrm{p}$ was less than 0.05. Data were processed, analyzed and figures were created in Excel (Microsoft Corp., Redmond, WA, USA), and Origin 2015 (Originlab Corp., Northampton, MA, USA).

\section{Results}

Effects of GS967 and mexiletine on $I_{\mathrm{NaL}}$ using conventional voltage clamp. First, the effects of GS967 and mexiletine on $\mathrm{I}_{\mathrm{NaL}}$ were studied under conventional voltage clamp conditions by applying $2 \mathrm{~s}$ duration depolarizations to $-20 \mathrm{mV}$ from the holding potential of $-120 \mathrm{mV}$ (Fig. 1). $1 \mu \mathrm{M}$ GS967 significantly reduced 


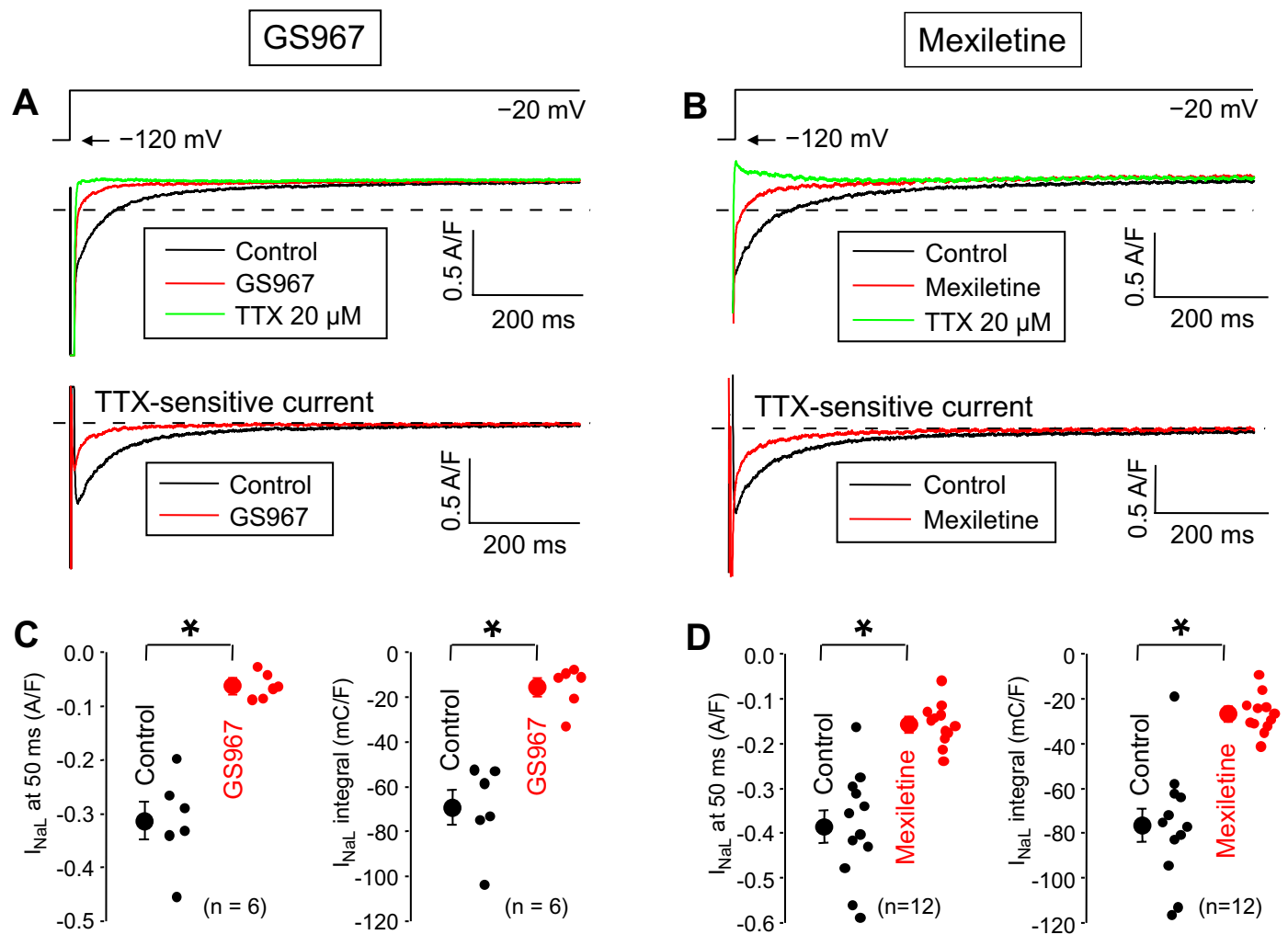

Figure 1. Effects of $1 \mu \mathrm{M}$ GS967 (A,C) and $40 \mu \mathrm{M}$ mexiletine (B,D) on $\mathrm{I}_{\mathrm{NaL}}$ under conventional voltage clamp conditions using test pulses of $2 \mathrm{~s}$ duration clamped to $-20 \mathrm{mV}$ from the holding potential of $-120 \mathrm{mV}$. At the end of each experiment the cells were superfused with $20 \mu \mathrm{M}$ TTX to dissect the remaining $\mathrm{I}_{\mathrm{NaL}}$. Dashed lines indicate zero current level. (A,B) Representative superimposed analogue records. (C,D) Average $\mathrm{I}_{\mathrm{NaL}}$ densities (measured at $50 \mathrm{~ms}$ ) and integrals (measured from $20 \mathrm{~ms}$ to $2 \mathrm{~s}$ ). Symbols and bars are mean \pm SEM, small dots represent individual data, numbers in parentheses indicate the number of myocytes studied, asterisks denote significant differences between data of the pre-drug control and the GS967- or mexiletine-treated groups.

the density of $\mathrm{I}_{\mathrm{NaL}}$, measured at $50 \mathrm{~ms}$ after the beginning of the pulse (from $-0.313 \pm 0.05$ to $-0.062 \pm 0.01 \mathrm{~A} / \mathrm{F}$, corresponding to an $80.4 \pm 2.2 \%$ reduction in the 6 myocytes studied). For comparison, this parameter was also significantly decreased by $40 \mu \mathrm{M}$ mexiletine from $-0.385 \pm 0.036$ to $-0.156 \pm 0.014 \mathrm{~A} / \mathrm{F}$ (reduction of $59.1 \pm 1.8 \%$, $\mathrm{n}=12$ ). Similar results were obtained when comparing the current integrals, i.e. the charge carried by the current with the exclusion of the initial $20 \mathrm{~ms}$. As determined from the same experiments, the current integrals were significantly decreased from $-69.1 \pm 7.9$ to $-15.4 \pm 3.9 \mathrm{mC} / \mathrm{F}(79.0 \pm 3.1 \%$ inhibition $)$ by GS967 and from $-76.4 \pm 7.6$ to $-26.7 \pm 2.6 \mathrm{mC} / \mathrm{F}(63.3 \pm 2.7 \%$ reduction $)$ by mexiletine.

Since class I antiarrhythmics are known to modify inactivation kinetics of $\mathrm{I}_{\mathrm{Nap}}$, the effects of $1 \mu \mathrm{M}$ GS967 and $40 \mu \mathrm{M}$ mexiletine on the voltage dependence of steady-state inactivation of $\mathrm{I}_{\mathrm{NaL}}$ was also examined using a conventional prepulse protocol. The amplitude of $\mathrm{I}_{\mathrm{NaL}}$ was determined at $50 \mathrm{~ms}$ after beginning of the test-pulse. Both GS967 and mexiletine caused a significant leftward shift in the steady-state inactivation curve (Fig. 2). The $\mathrm{V}_{0.5}$ value was shifted by -17.2 and $-13.5 \mathrm{mV}$ in the presence of GS967 and mexiletine, respectively. The slope factors of the curves were not influenced by GS967 or mexiletine.

Effects of GS967 and mexiletine under action potential voltage clamp conditions. Based on the non-equilibrium gating theory of Clancy et al., gating of the $\mathrm{Na}^{+}$channel is intimately influenced by the shape of the voltage protocol applied ${ }^{33}$. Therefore, the effects of GS967 and mexiletine on $\mathrm{I}_{\mathrm{NaL}}$ were studied also under action potential voltage clamp conditions using canonic mid-myocardial APs as command signals. $1 \mu \mathrm{M}$ GS967 and $40 \mu \mathrm{M}$ mexiletine dissected inward $\mathrm{I}_{\mathrm{NaL}}$ profiles having current densities (measured at $50 \%$ of $\mathrm{APD}_{90}$ ) of $-0.37 \pm 0.07$ and $-0.28 \pm 0.03 \mathrm{~A} / \mathrm{F}$, and current integrals of $-56.7 \pm 9.1$ and $-46.6 \pm 5.5 \mathrm{mC} / \mathrm{F}$, respectively. These differences, however, were not significant statistically. Since the $\mathrm{Ca}^{2+}$ and $\mathrm{K}^{+}$currents were previously blocked in these experiments, the recorded current profiles are considered as $\mathrm{I}_{\mathrm{NaL}}$ inhibited by GS967 and mexiletine during a regular ventricular AP (Fig. $3 \mathrm{~A}-\mathrm{C}$ ).

The total density and integral of $\mathrm{I}_{\mathrm{NaL}}$ in canine myocytes were estimated using concentration-response curves obtained with TTX, which was applied as a reference compound. The maximum value of the Hill-fit gave the total magnitude of $\mathrm{I}_{\mathrm{NaL}}$ (Fig. 3D,E). Comparing the respective current densities and integrals dissected by $1 \mu \mathrm{M}$ GS967 and $40 \mu \mathrm{M}$ mexiletine to these maximal values obtained with TTX, the inhibiting effects of GS967 and mexiletine could be expressed in a percentage form. Accordingly, GS967 and mexiletine blocked 88\% and 67\% 

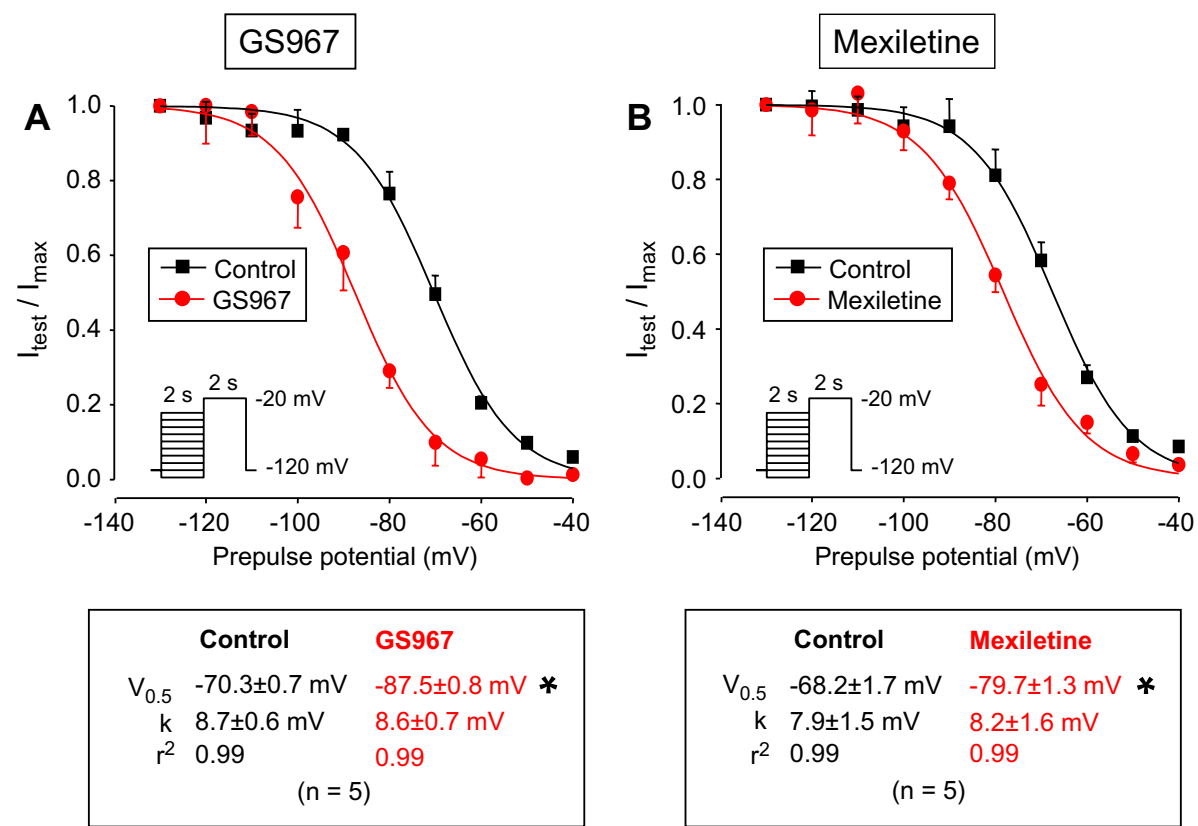

\begin{tabular}{|c|c|c|}
\hline & Control & Mexiletine \\
\hline $\mathrm{V}_{0.5}$ & $-68.2 \pm 1.7 \mathrm{mV}$ & $-79.7 \pm 1.3 \mathrm{mV} \boldsymbol{*}$ \\
\hline $\mathrm{k}$ & $7.9 \pm 1.5 \mathrm{mV}$ & $8.2 \pm 1.6 \mathrm{mV}$ \\
\hline$r^{2}$ & 0.99 & 0.99 \\
\hline \multicolumn{3}{|c|}{$(n=5)$} \\
\hline
\end{tabular}

Figure 2. Effects of $1 \mu \mathrm{M}$ GS967 (A) and $40 \mu \mathrm{M}$ mexiletine (B) on the voltage dependence of steady-state inactivation of $\mathrm{I}_{\mathrm{NaL}}$, determined using a conventional prepulse-protocol presented in the insets. $2 \mathrm{~s}$ long prepulses, ranging from -130 to $-40 \mathrm{mV}$ were followed by a test pulse clamped to $-20 \mathrm{mV}$ for $2 \mathrm{~s}$. Each $\mathrm{I}_{\mathrm{NaL}}$ amplitude $\left(\mathrm{I}_{\text {test }}\right)$ was normalized to the peak current measured after the $-130 \mathrm{mV}$ prepulse $\left(\mathrm{I}_{\max }\right)$ and these $\mathrm{I}_{\text {test }} / \mathrm{I}_{\max }$ ratios were plotted as a function of the corresponding prepulse-potential. Finally, data were fitted to a Boltzmann function and the results are given below the stead-state inactivation curves. Symbols and bars are mean \pm SEM values, numbers in parentheses indicate the number of myocytes studied, asterisks denote significant differences between data of the pre-drug control and the GS967- or mexiletine-treated groups.

of total $\mathrm{I}_{\mathrm{NaL}}$ density, and $78 \%$ and $64 \%$ of total $\mathrm{I}_{\mathrm{NaL}}$ integral, respectively. More importantly, the current profiles dissected by GS967 and mexiletine were different in shape. The GS967-sensitive current decreased monotonically during the AP, similarly to the TTX-sensitive current (not shown), while the mexiletine-sensitive current displayed a saddle-like profile. This difference is likely attributable to the threefold faster dissociation of GS967 than mexiletine from the $\mathrm{Na}^{+}$channel (see later).

Effects of GS967 and mexiletine on action potential upstroke. After determining the effects on $\mathrm{I}_{\mathrm{NaL}}$, the actions of GS967 and mexiletine on $\mathrm{I}_{\mathrm{NaP}}$ were studied and compared. Since direct measurement of cardiac $\mathrm{I}_{\mathrm{NaP}}$ is difficult at $37^{\circ} \mathrm{C}$, the maximum velocity of depolarization during the action potential upstroke $\left(\mathrm{V}^{+}{ }_{\text {max }}\right)$ was used as an approximate, although not linear, measure of $\mathrm{I}_{\mathrm{NaP}}{ }^{34-36}$. Due to the more physiological situation (e.g. higher stability) in multicellular cardiac preparations, these experiments were performed in right ventricular papillary muscles using sharp microelectrodes. As demonstrated in Fig. 4A,B, $40 \mu \mathrm{M}$ mexiletine significantly reduced $\mathrm{V}^{+}{ }_{\text {max }}$ in the entire frequency range applied under steady-state conditions, while this effect of GS967 was significant only at the shortest cycle lengths of 0.3 and $0.4 \mathrm{~s}$. This difference can well be explained by the faster offset kinetics of GS967 (Fig. 4C,D). The time constant of recovery of $\mathrm{V}^{+}{ }_{\max }$, determined following a constant $1 \mathrm{~Hz}$ stimulation was $110 \mathrm{~ms}$ for GS967, while almost three times longer, $289 \mathrm{~ms}$ for mexiletine. The onset kinetics of $\mathrm{V}^{+}$max block was studied by application of a constant stimulation rate at $2.5 \mathrm{~Hz}$ and the initial 40 APs were recorded. The onset rate constant was 5.3 AP for $1 \mu \mathrm{M}$ GS967 and 2.6 AP for $40 \mu \mathrm{M}$ mexiletine (Fig. 4E,F).

Effects of GS967 and mexiletine on APD. Although APD in right ventricular trabeculae was shortened by both GS967 and mexiletine in a reverse rate-dependent manner, this effect was statistically significant only at the longest constant cycle lengths above $1.5 \mathrm{~s}$ (Fig. 5).

Effects of GS967 and mexiletine on beat-to-beat variability of APD. Elevated beat-to-beat QT interval variability is a good predictor of ventricular arrhythmia in a wide variety of patients, while at a single cell level it translates into beat-to-beat variability of APD (also called short term variability, SV) - both parameters are considered as indicators of proarrhythmic risk ${ }^{37-40}$. In contrast to multicellular preparations, where the neighboring cells may effectively balance the individual differences in APD, SV is more pronounced in single cells, therefore the effects of GS967 and mexiletine were studied on SV in isolated ventricular cells, paced at a constant cycle length of $1 \mathrm{~s}$. Under these conditions SV was significantly decreased by $1 \mu$ M GS967 and $40 \mu \mathrm{M}$ mexiletine (reduction of $1.01 \pm 0.19$ and $0.63 \pm 0.02 \mathrm{~ms}$, respectively, corresponding to $42.1 \pm 6.5 \%$ and $24.6 \pm 12.8 \%$ decrease), while APD was moderately shortened by $32.5 \pm 6.9$ and $41.4 \pm 4.1 \mathrm{~ms}$, respectively, 
A
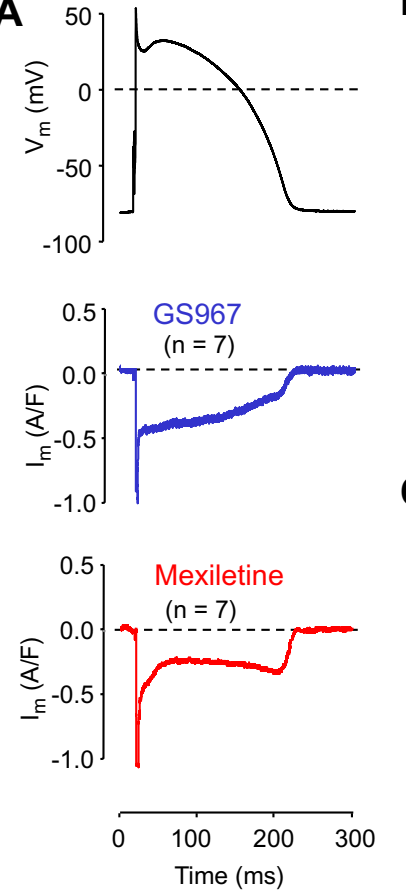

B

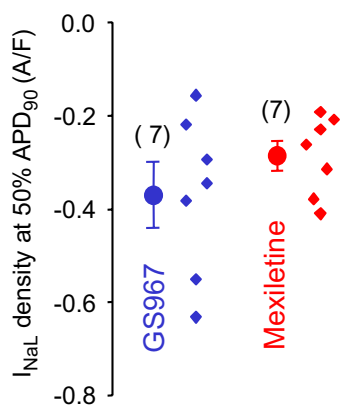

C

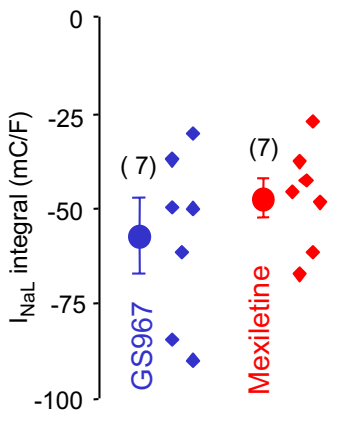

D
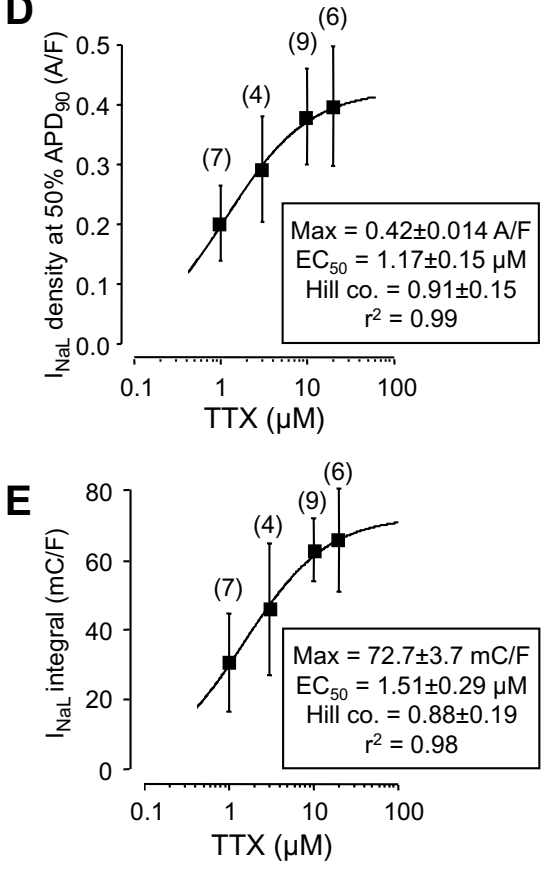

Figure 3. Effects of GS967 and mexiletine in isolated canine ventricular myocytes under action potential voltage clamp conditions. (A) Average membrane current profiles dissected by $1 \mu \mathrm{M}$ GS967 and $40 \mu \mathrm{M}$ mexiletine (in 7 myocytes in both cases), respectively, in the presence of $1 \mu \mathrm{M}$ nisoldipine $+1 \mu \mathrm{M}$ $\mathrm{E} 4031+100 \mu \mathrm{M}$ chromanol 293B. The command AP is shown above the current traces. (B) Current densities measured at $50 \%$ duration of $\mathrm{APD}_{90}$ of the command AP. (C) Current integrals from which the initial $20 \mathrm{~ms}$ period was excluded. (D,E) Concentration-dependent effects of TTX on the density and integral of $\mathrm{I}_{\mathrm{NaL}}$. The solid line was obtained by fitting data to the Hill equation. For conventional reasons the polarity was ignored in these latter plots. Symbols and bars denote mean \pm SEM values, small dots represent individual data, numbers in parentheses indicate the number of myocytes studied.

(all $p<0.05$ and $n=8$ ). All these effects were largely reversible upon washout (Fig. 6). Since APD itself is also known to affect the magnitude of SV, the term of relative SV (RSV) was introduced ${ }^{31,41}$. Accordingly, RSV $=\mathrm{dSV}$ / dAPD, i.e. the change in SV is normalized to that of APD. The value of RSV was significantly higher for GS967 than mexiletine $(0.039 \pm 0.007$ versus $0.015 \pm 0.007)$ predicting a better antiarrhythmic effectivity of GS967 than mexiletine.

\section{Discussion}

We studied and compared the effects of GS967 $(1 \mu \mathrm{M})$ to those of the class I/B antiarrhythmic drug mexiletine $(40 \mu \mathrm{M})$ on $\mathrm{I}_{\mathrm{NaL}}$ and $\mathrm{I}_{\mathrm{NaP}}$ in canine ventricular myocardium by combining the conventional microelectrode, voltage clamp and action potential voltage clamp techniques. It was found that GS967, which is generally considered as a selective blocker of $\mathrm{I}_{\mathrm{NaL}}{ }^{16}$, inhibits $\mathrm{I}_{\mathrm{NaP}}$ as well, similarly to the class I/B antiarrhythmic drug mexiletine, but with higher potency. Based on the hypothetically selective $\mathrm{I}_{\mathrm{NaL}}$ blocker nature of GS967, the drug was previously mentioned as a novel class VI antiarrhythmic agent ${ }^{42}$. However, without questioning the theoretical possibility of the concept for selective $\mathrm{I}_{\mathrm{NaL}}$ inhibition, an alternative approach should also be considered, since the concept whether $\mathrm{I}_{\mathrm{NaL}}$ can be blocked selectively is an interesting and still unresolved issue. There is evidence that $\mathrm{Na}^{+}$ current in cardiac tissues may also be conducted by $\mathrm{Na}^{+}$channels other than the cardiac specific $\mathrm{Na}_{\mathrm{v}} 1.5$ channels, which were suggested to contribute to both $\mathrm{I}_{\mathrm{NaP}}$ and $\mathrm{I}_{\mathrm{NaL}}$. However, proper functional evidence for their role is still lacking while considerable interspecies differences were observed ${ }^{43-51}$. If these channels play a role in $\mathrm{I}_{\mathrm{NaL}}$ but not in $\mathrm{I}_{\mathrm{NaP}}$ their pharmacological inhibition may result in selective $\mathrm{I}_{\mathrm{NaL}}$ blockade. However, GS967 has not been shown to inhibit these types of sodium channels but it was reported to inhibit cardiac type $\mathrm{Na}_{\mathrm{v}} 1.5$ channels $s^{9,10}$. Therefore, it is difficult to estimate the relative contribution of neuronal type $\mathrm{Na}^{+}$channels to the GS967-sensitive current.

$\mathrm{Na}_{\mathrm{v}} 1.5$ channels have complex and multiple open and closed states ${ }^{52}$ with different drug binding properties governing active, inactive and resting channel states. Accordingly, drugs interacting with the binding sites of the channels depending on their actual open or closed channel states may produce variable effects on $\mathrm{I}_{\mathrm{NaP}}$ and $\mathrm{I}_{\mathrm{NaL}}$. For example, when a drug binds rapidly and with high affinity to open and inactivated channel states, and it dissociates rapidly from closed resting channel states, it would not inhibit $\mathrm{I}_{\mathrm{NaP}}$ but $\mathrm{I}_{\mathrm{NaL}}$. This would be due to complete drug dissociation from its binding site in the resting closed states unless frequency was very high or at least the cycle length would be shorter than its dissociation from the channel. Consequently, whether a drug inhibits $\mathrm{I}_{\mathrm{NaP}}$ or $\mathrm{I}_{\mathrm{NaL}}$ selectively or both of them, largely depends on the stimulation protocol but not on existing 

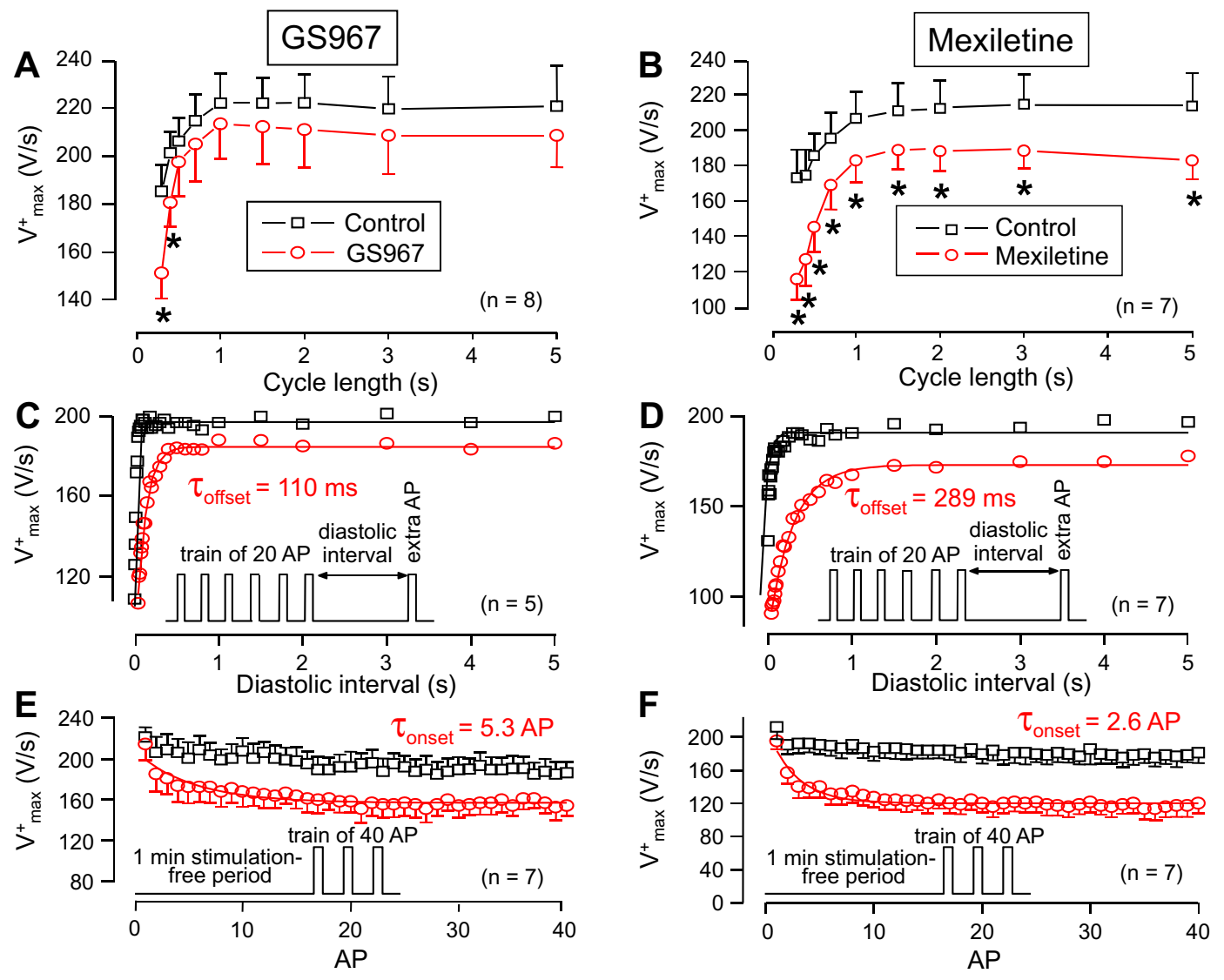

Figure 4. Effects of $1 \mu \mathrm{M}$ GS967 (A,C,E) and $40 \mu \mathrm{M}$ mexiletine (B,D,F) on the maximal rate of depolarization $\left(\mathrm{V}^{+}{ }_{\max }\right)$ measured in canine right ventricular trabeculae. $(\mathbf{A}, \mathbf{B})$ Cycle length-dependent effects on $\mathrm{V}^{+}{ }_{\max }$ under steady-state conditions. (C,D) Determination of offset kinetics of GS967 and mexiletine as indicated by the time-dependent restitution of $\mathrm{V}^{+}{ }_{\max }(\mathbf{E}, \mathbf{F})$ Determination of the onset kinetics of the $\mathrm{V}^{+}{ }_{\max }-$ block at $2.5 \mathrm{~Hz}$. The respective protocols are shown in the insets - for further details see Methods section. Solid lines were obtained by monoexponential fitting. Symbols and bars are mean \pm SEM, numbers in parentheses indicate the number of preparations studied, asterisks denote significant differences between data of the pre-drug control and the GS967- or mexiletine-treated groups.

specific $\mathrm{I}_{\mathrm{NaP}}$ or $\mathrm{I}_{\mathrm{NaL}}$ binding sites. Present results and other recently published data ${ }^{9,10}$ are consistent with this suggestion and do not support a mechanism which is based on specific $\mathrm{I}_{\mathrm{NaL}}$ inhibition that is distinctly different from class I/B antiarrhythmic actions described for drugs such as mexiletine ${ }^{14,52}$, lidocaine ${ }^{9,10,14}$, amiodarone $^{11}$ and ranolazine ${ }^{53}$. This approach is also in line with the reported high (38-fold) selectivity of ranolazine on $\mathrm{I}_{\mathrm{NaL}}$ over $\mathrm{I}_{\mathrm{NaP}}{ }^{2}$, which is intermediate (13-fold) for amiodarone ${ }^{3}$ and much lower (only threefold) for flecainide ${ }^{54}$.

In our experiments, both GS967 and mexiletine significantly depressed $\mathrm{V}^{+}{ }_{\max }$ at high stimulation rates. It was previously established that changes of $\mathrm{V}^{+}{ }_{\max }$ and $\mathrm{I}_{\mathrm{NaP}}$ are not linear and a relatively modest decrease of $\mathrm{V}^{+}{ }_{\max } \mathrm{can}$ represent robust depression of $\mathrm{I}_{\mathrm{NaP}}{ }^{35,36}$. Accordingly, the $20-30 \%$ reduction of $\mathrm{V}^{+}$max measured in the present study in papillary muscle preparations (at pacing cycle lengths of 0.3-0.4 s) following GS967 and mexiletine application can represent a similar degree of $\mathrm{I}_{\mathrm{NaP}}$ depression as the measured $60-80 \%$ reduction of $\mathrm{I}_{\mathrm{NaL}}$ obtained in ventricular myocytes. Therefore, in theory, neither GS967 nor mexiletine can be considered as "selective" $\mathrm{I}_{\mathrm{NaL}}$ inhibitors. However, when therapy is concerned - assuming that decreased $\mathrm{I}_{\mathrm{NaP}}$ is proarrhythmic, while reduced $\mathrm{I}_{\mathrm{NaL}}$ is antiarrhythmic - GS967, which has about threefold faster offset kinetics, can be more beneficial than mexiletine since $\mathrm{I}_{\mathrm{NaP}}$ would be affected in a lesser extent than $\mathrm{I}_{\mathrm{NaL}}$ by GS967 at normal or moderately enhanced heart rates.

On the basis of present and other results it is clear that GS967 affects $\mathrm{I}_{\mathrm{Nap}}$ in a strongly rate- and moderately species-dependent fashion. Similarly to our results, $\mathrm{V}^{+}{ }_{\max }$ was reduced by $0.3 \mu \mathrm{M}$ GS967 in murine myocytes ${ }^{55}$, while the same concentration of the drug failed to modify $\mathrm{V}^{+}{ }_{\max }$ in canine Purkinje strand ${ }^{56}$. On the other hand, GS967 shortened APD in a variety of preparations, including rat $^{57,58}$, murine ${ }^{55}$, rabbit $^{16,59}$ and human ${ }^{60}$ ventricular 

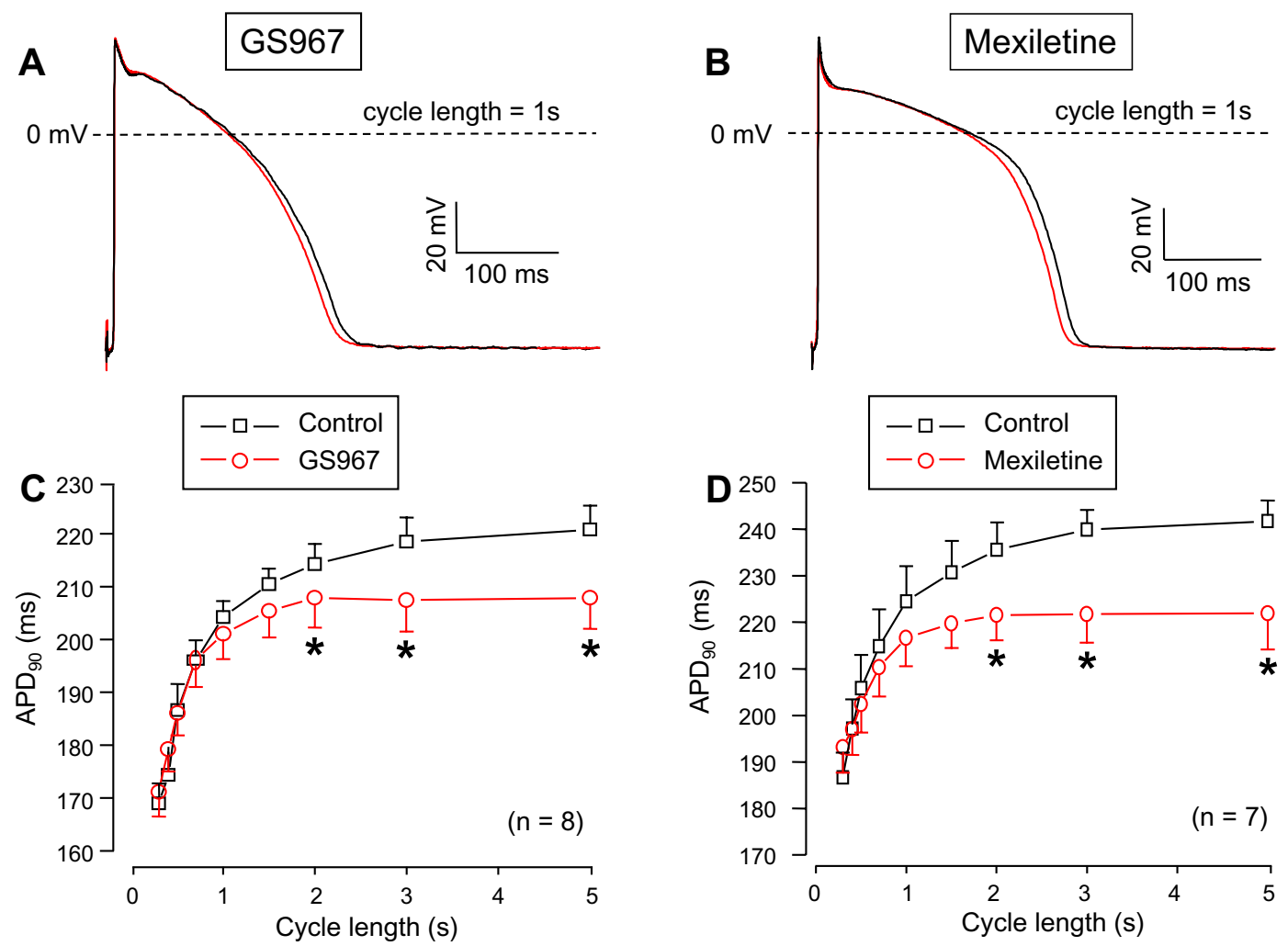

Figure 5. Cycle length-dependent effects of GS967 (A,C) and mexiletine (B,D) on AP duration measured at $90 \%$ of repolarization $\left(\mathrm{APD}_{90}\right)$ in canine right ventricular trabeculae under steady-state conditions. During the experiments the cycle length was gradually changed between 0.3 and $5 \mathrm{~s}$. $(\mathbf{A}, \mathbf{B})$ Representative superimposed analogue action potential pairs obtained at the constant pacing cycle length of $1 \mathrm{~s}$ before and after superfusion with $1 \mu \mathrm{M}$ GS967 or $40 \mu \mathrm{M}$ mexiletine. (C,D) Average rate-dependent APD values. Symbols and bars are mean \pm SEM, numbers in parentheses indicate the number of preparations studied, asterisks denote significant differences between data of the pre-drug control and the GS967- or mexiletine-treated groups.

cells within a wide concentration range $(0.1-1 \mu \mathrm{M})$ - similarly to the present observations in isolated canine ventricular cells. In our multicellular preparations, however, a significant APD shortening effect appeared only at cycle lengths longer than $1.5 \mathrm{~s}$. This can be explained by the well-known higher drug-sensitivity of single cells comparing to multicellular preparations. The reduction of $\mathrm{I}_{\mathrm{NaL}}$ by GS967 may result the GS967-induced shortening of the elongated APD, reduction of the enhanced dispersion and short term variability of repolarization, changes often preceding torsade de pointes arrhythmias ${ }^{38-40}$.

Taken together the present results and the literature, it is likely that a compound having kinetic properties similar to GS967 would be a very promising new antiarrhythmic agent, since several in vitro ${ }^{16-19,55-60}$ and in vivo ${ }^{57,61}$ studies support the potent antiarrhythmic activity of GS967. Its kinetic properties are better than those of mexiletine, as shown in this study, and also than those of ranolazine 9 , agents known to suppress $\mathrm{I}_{\mathrm{NaL}}$. GS967 had high brain penetration ${ }^{62}$, which can be utilized as a potential new antiepileptic compound ${ }^{63}$, and caused a profound use-dependent block on all sodium channel isoforms studied, making the compound prone for possible central nervous system side effects. It is unclear at present whether the effects of GS967 on the nervous system preclude the use of this drug as an antiarrhythmic therapeutic, however, a new agent exhibiting the same kinetic properties of GS967 without CNS side effects would represent a promising candidate for future development.

In summary, GS967 - similarly to mexiletine - inhibited both the peak and late components of $\mathrm{Na}^{+}$current and decreased beat-to-beat variability of APD. Based on its kinetic properties, GS967 should be classified as a new potent class I/B antiarrhythmic agent. The results of the present study also suggest that investigations of "selective" $\mathrm{I}_{\mathrm{NaL}}$ inhibitors should be carried out through a wide range of stimulation rates since the effect of drugs like GS967 or mexiletine, that possess fast offset kinetics of $\mathrm{I}_{\mathrm{NaP}}$ inhibition, can be misinterpreted. 

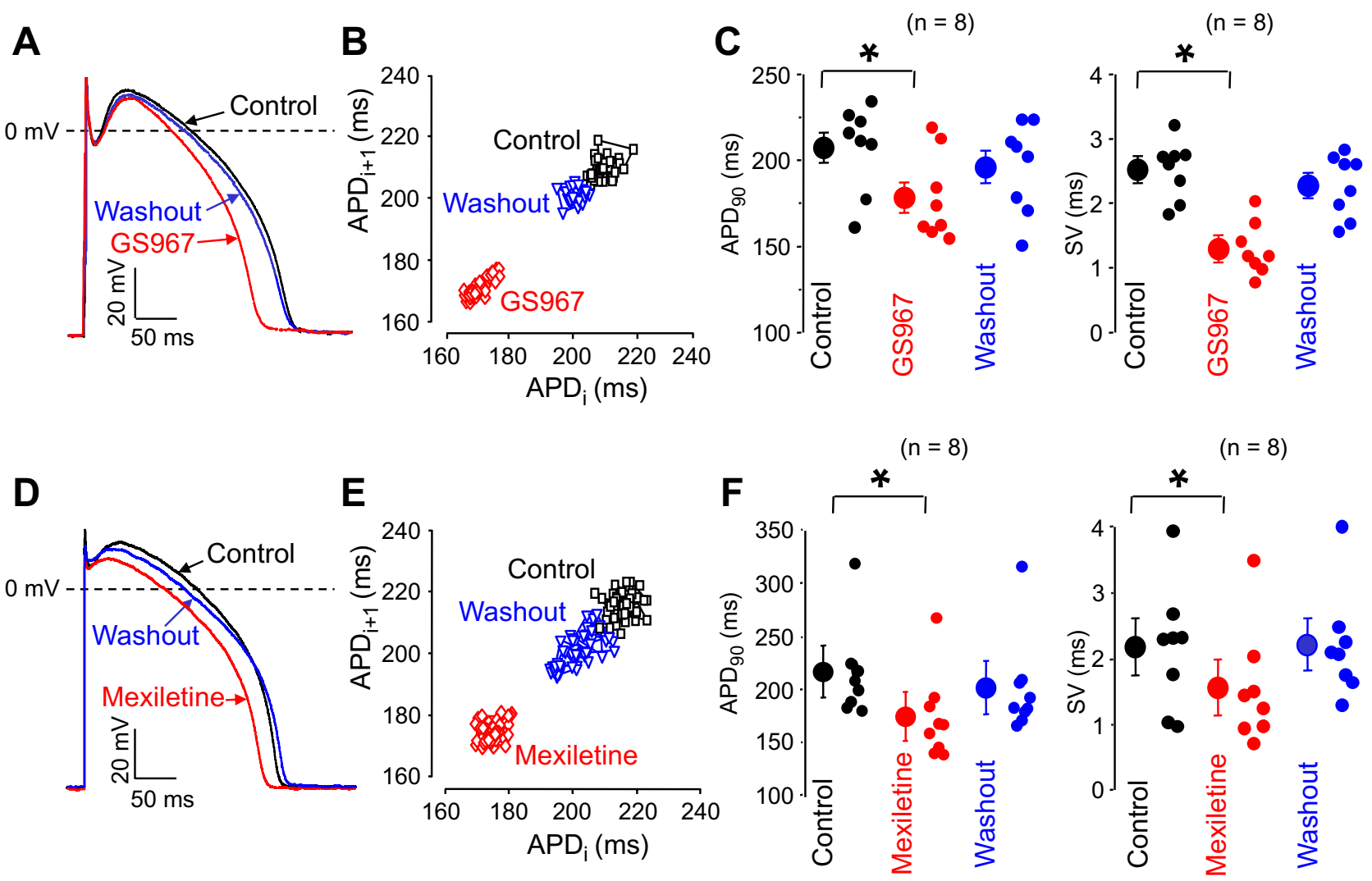

Figure 6. Reversible effects of GS967 (A-C) and mexiletine (D-F) on beat-to-beat variability of APD in isolated myocytes. Superimposed sets of action potentials (A,D) and Poincaré plots (B,E) obtained in control, following exposure to $1 \mu \mathrm{M}$ GS967 or $40 \mu \mathrm{M}$ mexiletine, and after washout of drugs. (C) and (F) show the average effects on beat-to-beat variability (SV) and APD. Symbols and bars are mean \pm SEM, small dots represent individual data, numbers in parentheses indicate the number of myocytes studied, asterisks denote significant differences between data of the pre-drug control and the GS967- or mexiletine-treated groups.

Received: 23 December 2020; Accepted: 26 March 2021

Published online: 05 May 2021

\section{References}

1. Valdivia, C. R. et al. Increased late sodium current in myocytes from a canine heart failure model and from failing human heart. J. Mol. Cell. Cardiol. 38, 475-483 (2005).

2. Undrovinas, A. I., Belardinelli, L., Undrovinas, N. A. \& Sabbah, H. N. Ranolazine improves abnormal repolarization and contraction in left ventricular myocytes of dogs with heart failure by inhibiting late sodium current. J. Cardiovasc. Electrophysiol. 17(Suppl 1), S169-S177 (2006).

3. Maltsev, V. A., Sabbah, H. N. \& Undrovinas, A. I. Late sodium current is a novel target for amiodarone: Studies in failing human myocardium. J. Mol. Cell. Cardiol. 33, 923-932 (2001).

4. Coppini, R., Santini, L., Olivotto, I., Ackerman, M. J. \& Cerbai, E. Abnormalities in sodium current and calcium homoeostasis as drivers of arrhythmogenesis in hypertrophic cardiomyopathy. Cardiovasc. Res. 116, 1585-1599 (2020).

5. Hu, R. M. et al. Mexiletine rescues a mixed biophysical phenotype of the cardiac sodium channel arising from the SCN5A mutation, N406K, found in LQT3 patients. Channels 12, 176-186 (2018).

6. Antzelevitch, C. \& Belardinelli, L. The role of sodium channel current in modulating transmural dispersion of repolarization and arrhythmogenesis. J. Cardiovasc. Electrophysiol. 17(Suppl 1), S79-S85 (2006).

7. Maltsev, V. A., Silverman, N., Sabbah, H. N. \& Undrovinas, A. I. Chronic heart failure slows late sodium current in human and canine ventricular myocytes: Implications for repolarization variability. Eur. J. Heart. Fail. 9, 219-227 (2007).

8. Shyrock, J. C., Song, Y., Rajamani, S., Antzelecitch, C. \& Belardinelli, L. The antiarrhythmogenic consequences of increasing late $\mathrm{I}_{\mathrm{Na}}$ in the cardiomyocyte. Cardiovasc. Res. 99, 600-611 (2013).

9. Potet, F., Vanoye, C. G. \& George, A. L. Jr. Use-dependent block of human cardiac sodium channels by GS967. Mol. Pharmacol. 90, 52-60 (2016).

10. Potet, F., Egecioglu, D. E., Burridge, P. W. \& George, A. L. Jr. GS-967 and eleclazine block sodium channels in human induced pluripotent stem cell-derived cardiomyocytes. Mol. Pharmacol. 98, 540-547 (2020).

11. Ghovanloo, M. R., Abdelsayed, M. \& Ruben, P. C. Effects of amiodarone and N-desethylamiodarone on cardiac voltage-gated sodium channels. Front. Pharmacol. 7, 39 (2016).

12. Salvage, S. C. et al. Multiple targets for flecainide action: Implications for cardiac arrhythmogenesis. Br. J. Pharmacol. 175, 12601278 (2018).

13. Varro, A., Elharrar, V. \& Surawicz, B. Frequency-dependent effects of several class I antiarrhythmic drugs on Vmax of action potential upstroke in canine cardiac Purkinje fibers. J. Cardiovasc. Pharmacol. 7, 482-492 (1985).

14. Varro, A., Nakaya, Y., Elharrar, V. \& Surawicz, B. Effect of antiarrhythmic drugs on the cycle length-dependent action potential duration in dog Purkinje and ventricular muscle fibers. J. Cardiovasc. Pharmacol. 8, 178-185 (1986). 
15. Cardiac Arrhythmia Suppression Trial (CAST) Investigators. Preliminary report: Effect of encainide and flecainide on mortality in a randomized trial of arrhythmia suppression after myocardial infarction. N. Engl. J. Med. 321, 406-412 (1989).

16. Belardinelli, L. et al. A novel, potent, and selective inhibitor of cardiac late sodium current suppresses experimental arrhythmias. J. Pharmacol. Exp. Ther. 344, 23-32 (2013).

17. Azam, M. A. et al. Effects of late sodium current blockade on ventricular refibrillation in a rabbit model. Circ. Arrhythm. Electrophysiol. 10, e004331 (2017)

18. del Canto, I. et al. Effects of the inhibition of late sodium current by GS967 on stretch-induced changes in cardiac electrophysiology. Cardiovasc. Drugs Ther. 32, 413-425 (2018).

19. Bossu, A. et al. Selective late sodium current inhibitor GS-458967 suppresses torsades de pointes by mostly affecting perpetuation but not initiation of the arrhythmia. Br. J. Pharmacol. 175, 2470-2482 (2018).

20. Horváth, B. et al. Late sodium current in human, canine and guinea pig ventricular myocardium. J. Mol. Cell. Cardiol. 139, 14-23 (2020).

21. Jost, N. et al. Ionic mechanisms limiting cardiac repolarization reserve in humans compared to dogs. J. Physiol. 591, 4189-4206 (2013).

22. Szabo, G. et al. Asymmetrical distribution of ion channels in canine and human left-ventricular wall: Epicardium versus midmyocardium. Pflügers. Arch. 450, 307-316 (2005).

23. Szentadrassy, N. et al. Apico-basal inhomogeneity in distribution of ion channels in canine and human ventricular myocardium. Cardiovasc. Res. 65, 851-860 (2005).

24. Jost, N. et al. Contribution of $\mathrm{I}_{\mathrm{Kr}}$ and $\mathrm{I}_{\mathrm{K} 1}$ to ventricular repolarization in canine and human myocytes: is there any influence of action potential duration? Basic. Res. Cardiol. 104, 33-41 (2009).

25. Hegyi, B. et al. $\beta$-adrenergic regulation of late $\mathrm{Na}^{+}$current during cardiac action potential is mediated by both PKA and CaMKII. J. Mol. Cell. Cardiol. 123, 168-179 (2018).

26. Horvath, B. et al. Dynamics of the late $\mathrm{Na}^{+}$current during cardiac action potential and its contribution to afterdepolarizations. J. Mol. Cell. Cardiol. 64, 59-68 (2013).

27. Hegyi, B. et al. Complex electrophysiological remodeling in postinfarction ischemic heart failure. Proc. Natl. Acad. Sci. USA. 115, E3036-E3044 (2018).

28. Hegyi, B. et al. $\mathrm{Ca}^{2+}$-activated $\mathrm{Cl}^{-}$current is antiarrhythmic by reducing both spatial and temporal heterogeneity of cardiac repolarization. J. Mol. Cell. Cardiol. 109, 27-37 (2017).

29. Banyasz, T. et al. Endocardial versus epicardial differences in L-type calcium current in canine ventricular myocytes studied by action potential voltage clamp. Cardiovasc. Res. 58, 66-75 (2003).

30. Bányász, T. et al. Action potential clamp fingerprints of $\mathrm{K}^{+}$currents in canine cardiomyocytes: Their role in ventricular repolarization. Acta. Physiol. Scand. 190, 189-198 (2007).

31. Szentandrássy, N. et al. Contribution of ion currents to beat-to-beat variability of action potential duration in canine ventricular myocytes. Pflügers Arch. 467, 1431-1443 (2015).

32. Virág, L. et al. Analysis of the contribution of $\mathrm{I}_{\mathrm{to}}$ to repolarization in canine ventricular myocardium. Br. J. Pharmacol. 164, 93-105 (2011).

33. Clancy, C. E., Tateyama, M., Liu, H., Wehrens, X. H. \& Kass, R. S. Non-equilibrium gating in cardiac sodium cahannels: An original mechanism of arrhythmia. Circulation 107, 2233-2237 (2003).

34. Hondeghem, L. M. Validity of $\mathrm{V}_{\max }$ as a measure of the sodium current in cardiac and nervous tissues. Biophys. J. 23, 147-152 (1978).

35. Sheets, M. F., Hanck, D. A. \& Fozzard, H. A. Nonlinear relation between $\mathrm{V}_{\max }$ and $\mathrm{I}_{\mathrm{Na}}$ in canine cardiac Purkinje cells. Circ. Res. 63, 386-398 (1988).

36. Cohen, C. J., Bean, B. P. \& Tsien, R. W. Maximal upstroke velocity as an index of available sodium conductance. Comparison of maximal upstroke velocity and voltage clamp measurements of sodium current in rabbit Purkinje fibers. Circ. Res. 54, 636-651 (1984).

37. Abi-Gerges, N., Valentin, J. P. \& Pollard, C. E. Dog left ventricular midmyocardial myocytes for assessment of drug-induced delayed repolarization: Short-term variability and proarrhythmic potential. Br. J. Pharmacol. 159, 77-92 (2010).

38. Hinterseer, M. et al. Usefulness of short-term variability of QT intervals as a predictor for electrical remodeling and proarrhythmia in patients with nonischemic heart failure. Am. J. Cardiol. 106, 216-220 (2010).

39. Tereshchenko, L. G. et al. Beat-to-beat three-dimensional ECG variability predicts ventricular arrhythmia in ICD recipients. Heart Rhythm 7, 1606-1613 (2010).

40. Thomsen, M. B. et al. Increased short-term variability of repolarization predicts d-sotalol-induced torsades de pointes in dogs. Circulation 110, 2453-2459 (2004).

41. Nánási, P. P., Magyar, J., Varró, A. \& Ördög, B. Beat-to-beat variability of cardiac action potential duration: Underlying mechanism and clinical implications. Canadian. J. Physiol. Pharmacol. 95, 1230-1235 (2017).

42. Karagueuzian, H. S., Pezhouman, A., Angelini, M. \& Olcese, R. Enhanced late Na and Ca currents as effective antiarrhythmic drug targets. Front. Pharmacol. 8, 36 (2017).

43. Rougier, J. S. \& Abriel, H. Role of "non-cardiac" voltage-gated sodium channels in cardiac cells. J. Mol. Cell. Cardiol. 53, 589-590 (2012).

44. Ahmad, S. et al. The functional consequences of sodium channel $\mathrm{Na}_{\mathrm{v}} 1.8$ in human left ventricular hypertrophy. ESC Heart. Fail. 6, 154-163 (2019).

45. Gaborit, N. et al. Regional and tissue specific transcript signatures of ion channel genes in the non-diseased human heart. J. Physiol. 582, 675-693 (2007).

46. Biet, M. et al. About half of the late sodium current in cardiac myocytes from dog ventricle is due to non-cardiac-type $\mathrm{Na}^{+}$channels. J. Mol. Cell. Cardiol. 53, 593-598 (2012).

47. Maier, S. K. et al. An unexpected role for brain-type sodium channels in coupling of cell surface depolarization to contraction in the heart. Proc. Natl. Acad. Sci. USA 99, 4073-4078 (2002).

48. Haufe, V. et al. Expression pattern of neuronal and skeletal muscle voltage-gated $\mathrm{Na}^{+}$channels in the developing mouse heart. J. Physiol. 564, 683-696 (2005).

49. Noujaim, S. F. et al. A null mutation of the neuronal sodium channel NaV1.6 disrupts action potential propagation and excitation-contraction coupling in the mouse heart. FASEB J. 26, 63-72 (2012).

50. Brette, F. \& Orchard, C. H. Density and sub-cellular distribution of cardiac and neuronal sodium channel isoforms in rat ventricular myocytes. Biochem. Biophys. Res. Commun. 348, 1163-1166 (2006).

51. Haufe, V. et al. Contribution of neuronal sodium channels to the cardiac fast sodium current $\mathrm{I}_{\mathrm{Na}}$ is greater in dog heart Purkinje fibers than in ventricles. Cardiovasc. Res. 65, 117-127 (2005).

52. Mangold, K. E. et al. Mechanisms and models of cardiac sodium channel inactivation. Channels 11, 517-533 (2017).

53. Szél, T. et al. Class I/B antiarrhythmic property of ranolazine, a novel antianginal agent, in dog and human cardiac preparations. Eur. J. Pharmacol. 662, 31-39 (2011).

54. Nagatomo, T., January, C. T. \& Makielski, J. C. Preferential block of late sodium current in the LQT3 DeltaKPQ mutant by the class I(C) antiarrhythmic flecainide. Mol. Pharmacol. 57, 101-107 (2000). 
55. Portero, V. et al. Anti-arrhythmic potential of the late sodium current inhibitor GS-458967 in murine Scn5a-1798insD1/2 and human SCN5A-1795insD1/2 iPSC-derived cardiomyocytes. Cardiovasc. Res. 113, 829-838 (2017).

56. Sicouri, S., Belardinelli, L. \& Antzelevitch, C. Antiarrhythmic effects of the highly selective late sodium channel current blocker GS-458967. Heart Rhythm 10, 1036-1043 (2013).

57. Chi, L. et al. Inhibition of late Na current, a novel target to improve diastolic function and electrical abnormalities in Dahl saltsensitive rats. Am. J. Physiol. Heart. Circ. Physiol. 310, H1313-H1320 (2016).

58. Pezhouman, A. et al. Selective inhibition of late sodium current suppresses ventricular tachycardia and fibrillation in intact rat hearts. Heart Rhythm 11, 492-501 (2014).

59. El-Bizri, N., Li, C. H., Liu, G.-X., Rajamani, S. \& Belardinelli, L. Selective inhibition of physiological late Na current stabilizes ventricular repolarization. Am. J. Physiol. Heart. Circ. Physiol. 314, H236-H245 (2018).

60. Ferrantini, C. et al. Late sodium current inhibitors to treat exercise-induced obstruction in hypertrophic cardiomyopathy: An in vitro study in human myocardium. Br. J. Pharmacol. 175, 2635-2652 (2018).

61. Bonatti, R. et al. Selective late sodium current blockade with GS-458967 markedly reduces ischemia-induced atrial and ventricular repolarization alternans and ECG heterogeneity. Heart Rhythm 11, 827-1835 (2014).

62. Koltun, D. O. et al. Discovery of triazolopyridine GS-458967, a late sodium current inhibitor (Late $\left.\mathrm{I}_{\mathrm{Na}} \mathrm{i}\right)$ of the cardiac NaV 1.5 channel with improved efficacy and potency relative to ranolazine. Bioorg. Med. Chem. Lett. 26, 3202-3206 (2016).

63. Anderson, L. L., Hawkins, N. A., Thompson, C. H., Kearney, J. A. \& George, A. L. Jr. Unexpected efficacy of a novel sodium channel modulator in Dravet syndrome. Sci. Rep. 7, 1682 (2017).

\title{
Acknowledgements
}

This work was funded by the National Research Development and Innovation Office (NKFIH-PD120794 and NKFIH-FK128116 to B.H., NKFIH-K119992 to A.V. and NKFIH K 128851 to I.B.) and by the Hungarian Academy of Sciences (János Bolyai Research Scholarship to B.H.). Further support was obtained from the Thematic Excellence Programme of the Ministry for Innovation and Technology in Hungary (TKP-2020-NKA-04), within the framework of the Space Sciences thematic programme of the University of Debrecen, and from the GINOP2.3.2.-15-2016-00040 and GINOP-2.3.2.-15-2016-00048, projects, co-financed by the European Union and the European Regional Development Fund. The work was also supported by the Ministry of Human Capacities Hungary (EFOP-3.6.2-16-2017-00006, EFOP 3.6.2 16 2017-00006, EFOP 3.6.3-VEKOP-16-2017-00009, 20391 3/2018/FEKUSTRAT, ÚNKP-20-2 and ÚNKP-20-3 projects), and by grant from the Stipendium Hungaricum program offered by the Hungarian State (to MNK).

\section{Author contributions}

Preparation of the manuscript: P.P.N., A.V., B.H. Design of experimental protocols: T.B., J.M., I.B. Action potential voltage clamp experiments: T.H., C.D., D.K. Conventional voltage clamp experiments: M.N.K., J.P., N.S. Action potential recording from multicellular preparations: T.Á.L., R.V., E.F., L.T. Action potential recording from isolated canine myocytes preparations: T.H., K.K., T.M. Statistical analysis: N.J., J.A., L.V.

\section{Competing interests}

The authors declare no competing interests.

\section{Additional information}

Correspondence and requests for materials should be addressed to A.V. or P.P.N.

Reprints and permissions information is available at www.nature.com/reprints.

Publisher's note Springer Nature remains neutral with regard to jurisdictional claims in published maps and institutional affiliations.

\begin{abstract}
Open Access This article is licensed under a Creative Commons Attribution 4.0 International License, which permits use, sharing, adaptation, distribution and reproduction in any medium or format, as long as you give appropriate credit to the original author(s) and the source, provide a link to the Creative Commons licence, and indicate if changes were made. The images or other third party material in this article are included in the article's Creative Commons licence, unless indicated otherwise in a credit line to the material. If material is not included in the article's Creative Commons licence and your intended use is not permitted by statutory regulation or exceeds the permitted use, you will need to obtain permission directly from the copyright holder. To view a copy of this licence, visit http://creativecommons.org/licenses/by/4.0/.
\end{abstract}

(C) The Author(s) 2021 